\title{
The Role of Precedents in Repeated Litigation
}

\author{
Yeon-Koo Che \\ University of Wisconsin, Madison \\ Jong Goo Yi \\ Shearman \& Sterling
}

\section{Introduction}

One of the most distinctive characteristics of the common law system is that the judiciary is an important "source of law."l While judges in the civil law tradition mostly interpret the statutory law, common law judges can make the law by creating precedents (stare decisis). ${ }^{2}$ Once established, a precedent requires judges in subsequent cases to follow the precedent when factual situations are not significantly different.

In this article, we consider precedents in the context of repeated litigation where a series of claimants bring suits against a single defendant on related issues. Repeated litigation of this type is quite common and increasingly significant. In many product liability, securities fraud, antitrust, and environmental cases, a defendant, typically a large corporation, is sued over an extended period of time by numerous plaintiffs allegedly hurt by the defen-

Both authors are grateful to Tim Bresnahan, Ian Gale, Mitch Polinsky, Larry Samuelson, Steven Shavell, Ed Steinmueller, Joe Stiglitz, an anonymous referee, and seminar participants at Korea University and Stanford University for helpful comments. Both authors' research on this article was supported by the John M. Olin Program in Law and Economics at Stanford Law School. The first author also acknowledges financial support from the Center for Economic Policy Research at Stanford University.

1. The U.S., England, Ireland, Canada, Australia, and New Zealand are in the common law tradition, while most of Western Europe, Central and South America, Africa, and Asia are in the civil law tradition.

2. For more details on the distinction between the common law system and the civil law system, see Merryman (1985). 
dant's unlawful conduct or defective products. In the product liability area, for instance, thousands of claims have been filed against producers of asbestos, cigarettes, motor vehicles, or pharmaceuticals. Examples include the Dalkon Shield, Benedectin, and Agent Orange. ${ }^{3}$ Precedents can have distinctive strategic implications for litigating parties in this kind of situation. Once a case goes to trial, a precedent will be set and have a lasting effect on successive trial outcomes. For a repeat player, then, going to trial means not only facing a particular court decision, but also setting a good or bad precedent for future cases. Recognizing this, the players will alter their strategies in pretrial bargaining, based on their expectation of the precedent. Our objective here is to identify the ways in which precedents affect litigating parties' bargaining strategies and thereby their settlement behavior.

We apply the two-period litigation model developed in Che and Yi (1990), where two plaintiffs, one in each period, file claims against a single defendant over related issues. To do a meaningful analysis on settlement, we adopt an asymmetric information model where the defendant does not have perfect information on each plaintiff's damage.

We focus on two forms of decision inertia created by precedents: (i) correlated decisions and (ii) correlated damages. The term "correlated decisions" refers to a situation where a decision favoring a party in one case (positively) affects the party's chance to win in a later case. This feature of precedents follows from the fact that common law judges must apply the holdings of a prior case to subsequent factually similar cases. ${ }^{4}$ Sometimes, correlation of decisions can result from a court's applying "collateral estoppel doctrine" (or "issue exclusion"), which prohibits parties from relitigating the common issue once ruled on by previous courts. ${ }^{5}$

To a lesser degree, we postulate that "correlated damages" can be regarded as another characteristic of precedents in the repeated litigation context. Although courts are not legally bound by the previous judgment awards, their judgments are likely to be correlated over similar cases as they apply common rules in assessing damages. Then, a court's judgment in one case can serve as

3. One notable example is Johns-Manville Corporation, which was a major manufacturer of asbestos products. In 1982, it filed for bankruptcy under the pressure of the overwhelming number of claims. A series of private antitrust litigations against IBM in the late 1970 s after the U.S. government's initial action provides another example. For details, see Dungworth (1988).

4. To follow the strict legal interpretation, we must distinguish between the actual holding of the case and the ratio decidendi. The former denotes a precise point at issue while the latter is a generally applicable rule of law on which the court says the holding is based. To be precise, the courts must follow the ratio decidendi of the previous case in reaching a particular holding in a similar case (Llewellyn, 1989). Therefore, the correlation between court decisions is not perfect. Also, similar as it may appear, each case involves somewhat different factual situations. Therefore, a judge presiding over a subsequent case has some discretion to distinguish the case from the previous one and fashion its holdings accordingly.

5. Certain conditions must be satisfied before the doctrine applies: (i) the issue of the second period must be identical with the issue decided in the prior proceeding; (ii) the issue was necessarily decided in the prior proceeding; (iii) the litigant had a full and fair opportunity to litigate the issue in the prior proceeding. For details, see Friedenthal, Kane, and Miller (1985). 
a form of a precedent (or a reference point) for a repeat player in figuring out the judgment pattern of courts for future cases.

Often these two types of correlation exist simultaneously in some areas of repeated litigation, such as asbestos cases. In this article, however, for analytical clarity, we examine the two features of precedents separately. We first investigate how correlated decisions affect litigants' incentives for settlement. We show that there is some critical threshold level in the defendant's winning probability against the first plaintiff such that when his winning probability is higher (lower) than this threshold level, the equilibrium settlement rate will be higher (lower) than it would be when there is no precedent. This can be easily explained. When the defendant is less likely to win at trial against the first plaintiff (relative to some threshold winning probability), he has an incentive to make a larger settlement offer relative to the situation where there is no precedent. This is because if the case goes to trial in the first period, the defendant (with a small winning probability) will face the possibility of an unfavorable precedent being set, which will hurt him in the second period. To avoid this unwelcome consequence, the defendant will make a higher settlement offer in the first period. This will increase the first period's settlement rate. Conversely, if the defendant's winning probability is high in the first period, he is more likely to risk trial, and more so as the precedential value increases.

Two interesting implications can be obtained from this observation. First, when the parties can influence a trial outcome through litigation efforts, they will front-load their efforts to the initial (precedent-setting) stage, because setting a favorable precedent is more effective than fighting against an unfavorable one already set. This might explain why landmark cases often lead to intensive campaigns by those most likely to be affected by the resulting precedents.

Second, the settlement behavior under correlated decisions indicates that the defendant is more aggressive against a plaintiff with a low winning probability than against the one with a high winning probability. The defendant's differing responses to plaintiffs based on their likelihood of prevailing at trial may imply that correlated decisions discourage nuisance suits (just as the European fee system does).

Finally, when damages are correlated across periods, we find that the initial trial gives the defendant a valuable learning opportunity, enabling him to make an offer better tailored to the subsequent plaintiff. This learning opportunity may induce the defendant to risk trial more often than otherwise.

There have been some legal studies on the collateral estoppel doctrine, 6 but most of them are concerned about the fairness issue arising from nonmutual application of the doctrine. A couple of recent articles (Spurr, 1991; Note, 1992) have formally analyzed the implications of the doctrine on the welfare of disputing parties. In particular, Note (1992) identified the possibility that

6. Early contributions include Currie (1957) and Polasky (1954). More recent ones are George (1980), Ratliff (1988), and Schroeder (1982). 
defendants facing a sequence of plaintiffs are extorted through settlement by the initial plaintiffs when the collateral estoppel doctrine is applied unfavorably against the defendants. Our approach differs from these previous ones in that we attempt to draw implications on the settlement incentives, intertemporal allocation of litigation efforts, and nuisance suits.

This article is organized as follows. Section 2 briefly reviews a one-period litigation problem. Section 3 introduces repeated litigation with correlated decisions and examines parties' settlement behavior, and Section 4 explores further implications of correlated decisions. In Section 5, we provide a numerical example to illustrate our findings. Finally, Section 6 examines correlated damages.

\section{A Review of One-Period Litigation}

In this section, we review a one-period problem. This review provides some useful results that are used in our analysis on precedents. Also, the one-period problem later serves as a point of contrast, because, absent precedents, the two-period model is equivalent to a replication of two one-period games.

The parties are risk neutral, and the American fee system under which each party bears his own litigation costs is adopted. The following notation is used throughout:

$w=$ plaintiff's damage, distributed over $[0, \bar{w}]$

$F(w)=$ a twice differentiable distribution function of $w$ with a positive density $f$.

$s=$ the defendant's settlement offer.

$c=$ the plaintiff's litigation costs.

$d=$ the defendant's litigation costs.

$p=$ the plaintiff's winning probability.

A litigation cycle consists of three stages. In the first stage, the plaintiff is privately informed about $w$, while the defendant knows only its probability distribution, $F(w)$. In the second stage, the defendant makes a settlement offer $s$ on a take-it-or-leave-it basis. In the last stage, the game ends if the plaintiff accepts the offer, but the case goes to trial if the plaintiff rejects it. This oneperiod problem is similar to Bebchuk (1984) in that pretrial bargaining involves an uninformed party making an offer to an informed party.

We use backward induction to solve for each party's optimal decision rule.? In the last stage, the plaintiff would accept an offer if and only if it is no less than what she expects to gain from trial. That is, an optimal decision rule for plaintiff, [P], with damage $w$ is

$$
\text { Accept } s(\geq 0), \quad \text { if and only if (iff) } s \geq p w-c .^{8}
$$

7. The equilibrium concept we use is that of Perfect Bayesian Equilibrium.

8. We restrict attention to nonnegative offers because the plaintiff can always refuse a negative offer and either go to trial or drop the case (when the expected net trial recovery is negative). 
Let $w(s) \equiv \frac{s+c}{p}$ denote a threshold-type plaintiff, who is indifferent between settling and going to trial at the given $s$. In the second stage, the defendant makes a settlement offer $s$ to minimize the expected loss. Since there is a one-to-one correnspendence between $s$ and the threshold type $w(s)$, without loss of generality, the defendant can be regarded as picking the threshold type $\hat{w}=w(s)$. It is convenient to work with this threshold level rather than the settlement offer, since the equilibrium value of the threshold level will provide an intuitive measure of the likelihood of settlement. (The settlement likelihood will be simply $F(\hat{w})$, the probability that the plaintiff has lower judgment than the threshold type. $)^{9}$ Let $s(\hat{w})=\hat{w} p-c$ denote the minimum offer needed to induce the threshold type to settle. Then, the defendant's decision rule, [D], can be expressed as

[D]

$$
\begin{aligned}
L^{*}(p)= & \min _{\hat{w} \geq c / p} L(\hat{w} ; p)=s(\hat{w}) F(\hat{w})+d[1-F(\hat{w})] \\
& +p \int_{\hat{w}}^{\dot{w}} w d F(w) .
\end{aligned}
$$

The defendant's expected loss consists of three elements: the expected settlement payment, the expected litigation costs, and the expected judgment at trial.

Let $\hat{w}^{*}(p)$ denote a solution to [D]. Then, the plaintiff's expected utility in the first stage is given by

$$
U^{*}(p) \equiv L^{*}(p)-\left[1-F\left(\hat{w}^{*}(p)\right)\right][c+d]
$$

which is the expected loss $L(p)$ less the expected litigation costs borne by both parties.

The first-order condition for an interior optimum of $[D]$ is given by

$H\left(\hat{w}^{*}\right)=\frac{c+d}{p}$

where $H=\frac{F}{f}$ is the inverse hazard rate. Throughout this article, in considering the defendant's optimization problems, we restrict attention to interior solutions. ${ }^{10}$

9. A settlement offer can be a misleading indicator for the settlement probability. When the plaintiff's winning probability increases, in equilibrium the defendant may increase his offer, and yet the settlement rate can go down, since the plaintiff now demands more.

10. This is just to simplify our exposition and does not change the qualitative results of this article. As can be easily checked, incorporating comer solutions just changes strict inequalities to weak inequalities in all the subsequent propositions. 
This first-order condition is similar to the one obtained in Bebchuk (1984) and has a similar interpretation: The defendant optimally balances benefits and costs of increasing the settlement offer. An incremental increase in the settlement offer, say by $d s$, increases the defendant's loss for the settlement range [which accounts for the whole inframarginal types whose measure is $F(w(s))]$. But it also increases the settlement rate by $\frac{f(w(s))}{p} d s\left(=\frac{d F(w(s))}{d s}\right)$ and enables the defendant to save the litigation costs $c+d$ at the margin. ${ }^{11}$ At the optimum, these marginal benefits must equal the marginal costs. This firstorder condition is necessary for the offer to be optimal. It is also sufficient if the inverse hazard rate is strictly increasing. 12 Roughly speaking, this implies that the marginal cost is increasing in the settlement offer. This assumption is labeled as [A1] and used throughout the article.

The following lemma reports some important comparative static results that we will refer to in later sections. All the proofs, including that of Lemma 1, are relegated to the Appendix.

Lemma 1. Suppose [D] has a unique solution for $p$, then (i) $\hat{w}^{*}$ is strictly decreasing in $p$; (ii) $L^{*}$ is strictly increasing in $p$.

The second statement implies that the defendant's welfare is reduced when the trial prospect becomes less favorable. The argument for the first statement is less trivial. It implies that settlement is less likely the more likely is the plaintiff to win the trial. Intuitively, with higher $p$, the defendant finds it harder to get his offer accepted because the plaintiff demands more to forgo a trial option (which has become more favorable). Therefore, at the same threshold level $\hat{w}$ the marginal benefits from increasing $s$ are reduced, while its marginal costs remain the same. Thus, the equilibrium settlement rate goes down. ${ }^{13}$

\section{Settlement Behavior under Correlated Decisions}

In this section, we extend the one-period model to study the effect of correlated decisions. In this extension, the litigation cycle described in the previous section is repeated twice. To model correlated decisions, we assume that the second plaintiff's winning probability depends on the outcome of the first case: Her winning probability increases (decreases) when the first plaintiff

11. The reason that the defendant saves the whole litigation cost (not just his portion $d$ ) through settlement is because, being the first mover in the bargaining game, he extracts all the surplus the plaintiff receives from settlement. Although this particular result appears model-specific, it is not essential to the central points we make in this paper.

12. This condition roughly says that the density function $f(\cdot)$ does not grow too fast. It is satisfied with most of the well-known distribution functions, including the uniform, exponential, and normal distributions.

13. Whether the defendant would want to raise his settlement offer as $p$ increases depends on the elasticity $\varepsilon_{H}$ of $H$ with respect to $w$. The equilibrium settlement offer will increase in $p$ iff $\varepsilon_{H} \geq 1$. 
wins (loses), while it remains unchanged when the first case is settled. Let $p_{1}$, $p_{2}$ denote the first and second plaintiff's winning probabilities, respectively. Formally, then, $p_{2}$ is determined in the following way:

$p_{2} \equiv \begin{cases}p_{\mathrm{S}}=p, & \text { if the first case is settled ("S"); } \\ p_{\mathrm{W}}=p+\varepsilon_{p}, & \text { if the first plaintiff wins trial ("W"); } \\ p_{\mathrm{L}}=p-\varepsilon_{d}, & \text { if the first plaintiff loses trial ("L") }\end{cases}$

where $p$ and $\varepsilon$ are such that $0<p-\varepsilon_{d}<p+\varepsilon_{p}<1$. From now on, all the other variables will be similarly subscriptized by $1,2, \mathrm{~S}, \mathrm{~W}$, and $\mathrm{L}$. Here the parameters $\varepsilon_{p}$ and $\varepsilon_{d}$ measure the precedential effect of the first trial on the second case. Specifically, $\varepsilon_{p}$ denotes an added winning probability for the second plaintiff when the first plaintiff wins trial, which may result from an application of the so-called "offensive collateral estoppel doctrine." Under the doctrine, the defendant is prohibited from relitigating an issue decided against him in an earlier trial. Similarly, $\varepsilon_{d}$ can measure the likelihood of the application of the "defensive collateral estoppel doctrine," which prohibits the second plaintiff from relitigating an issue decided against the first plaintiff. In most of this article, we take the precedential effect to be "mutual" (i.e., $\varepsilon_{p}, \varepsilon_{d}$ $>0$ ) and, when simplicity serves exposition, "symmetric" (i.e., $\varepsilon_{p}=\varepsilon_{d}=\varepsilon$ ). However, as a thought experiment-and, more importantly, as reflection of current debates ${ }^{14}$ - we also consider extreme cases where the precedential effect is "nonmutual" (i.e., $\varepsilon_{d}=0, \varepsilon_{p}>0$; or $\varepsilon_{d}>0, \varepsilon_{p}=0$ ).

To analyze the effects of correlated decisions, we use backward induction by considering the second-period problem first. In the second period, parties face the same problems (and thus adopt the same decision rules, [P] and [D]) as in the one-period game, except for the fact that they now inherit different trial prospects (winning probabilities) depending on the first-period outcome. Therefore, the defendant's optimal offer in the second period is characterized as the following first-order conditions:

$H\left(\hat{w}_{i}\right)=\frac{c+d}{p_{i}}$

where $i=\mathrm{W}, \mathrm{L}$, or S. Let $L_{i}$ denote the defendant's second-period loss following the first-period outcome $i$ for $i=\mathrm{W}, \mathrm{L}, \mathrm{S}$. Then, we obtain the following result by applying Lemma 1.

Corollary 1. If the precedential effect is mutual $\left(\varepsilon_{p}, \varepsilon_{d}>0\right)$, then $(i) \hat{w}_{\mathrm{L}}>$ $\hat{w}_{\mathrm{S}}>\hat{w}_{\mathrm{w}}$; and (ii) $L_{\mathrm{L}}<L_{\mathrm{S}}<L_{\mathrm{w}}$. On the other hand, if there is no prodefendant precedential value $\left(\varepsilon_{d}=0\right)$, then $\hat{w}_{\mathrm{L}}=\hat{w}_{\mathrm{S}}$ and $L_{\mathrm{L}}=L_{\mathrm{S}}$, while if there is no pro-plaintiff precedential value $\left(\varepsilon_{p}=0\right)$, then $\hat{w}_{S}=\hat{w}_{\mathrm{W}}$ and $L_{\mathrm{s}}=L_{\mathrm{W}}$.

14. For discussion of current debates on the mutuality of collateral estoppel doctrine, see the concluding remarks in Section 7. 
Note that the second plaintiff reacts to a given settlement offer differently. In the case of the mutual precedential effect, she is less willing to settle when the first plaintiff wins trial (i.e., demands more to settle) and more willing to settle when the first plaintiff loses. Her winning probability, however, will remain unaffected if the first case is settled. Consequently, the settlement rate is the highest, lowest, and in between in the second period if the first plaintiff loses, wins, and settles, respectively.

Let $L_{\mathrm{T}}$ and $U_{\mathrm{T}}$ denote the defendant's expected second-period loss and the second plaintiff's expected utility when the first case is tried. Then, $L_{\mathrm{T}}=$ $p_{1} L_{\mathrm{W}}+\left(1-p_{1}\right) L_{\mathrm{L}}$, and $U_{\mathrm{T}}=p_{1} U_{\mathrm{W}}+\left(1-p_{\mathrm{L}}\right) U_{\mathrm{L}}$, where $L_{i}$ and $U_{i}$ are defined in the same way as $L^{*}$ and $U^{*}$ with $p$ replaced by $p_{i}$.

Now, we are in a position to discuss the first-period problem. Since the first plaintiff is a short-run player, her optimal decision is the same as in the oneperiod game (i.e., [P]). But the defendant is not myopic. He takes account of the long-term consequences when determining the first-period settlement offer. Formally, the defendant's problem is represented by

$$
\begin{gathered}
\min _{\hat{w}_{1} \geq c / p} L_{1}\left(\hat{w}_{1}, p_{1}\right)=\left[s\left(\hat{w}_{1}\right)+L_{S}\right] F\left(\hat{w}_{1}\right)+\left[1-F\left(\hat{w}_{1}\right)\right] \\
\times\left[L_{\mathrm{T}}+d\right]+p_{1} \int_{\hat{w}_{1}}^{\dot{w}} w d F(w) .
\end{gathered}
$$

This ex ante loss function has the second-period loss terms $L_{\mathrm{S}}$ and $L_{\mathrm{T}}$ added to the one-period loss function in [D]; the defendant, when making an offer, takes its second-period consequences into consideration. The first-order condition for [D1] is

$H\left(\hat{w}_{1}\right)=\frac{c+d+L_{\mathrm{T}}-L_{\mathrm{S}}}{p_{1}}$

Compared with the first-order condition for [D], the only difference here is the additional term, $L_{T}-L_{S}$, in the right-hand side. This term represents the cost of setting a precedent. When it is positive, the precedent is unfavorable to the defendant; when negative, it is favorable. The cost of setting a precedent depends on the first-period winning probability. It follows from Corollary 1 and the definition of $L_{\mathrm{T}}$ that, when the precedential effect is mutual, precedent is unfavorable (favorable) if $p_{1}$ is sufficiently high (low).

Proposition 1. When the precedential effect is mutual $\left(\varepsilon_{p}, \varepsilon_{d}>0\right)$, there exists a threshold probability $\hat{p}_{1} \in(0,1)$ such that the first-period equilibrium settlement offer and the settlement rate are higher with correlated decisions than without, if and only if the first plaintiff's winning probability is higher than the threshold level, $\hat{p}_{1}$. With nonmutual offensive collateral estoppel 
$\left(\varepsilon_{p}>0, \varepsilon_{d}=0\right), \hat{p}_{1}=0$, while $\hat{p}_{1}=1$ with nonmutual defensive collateral estoppel $\left(\varepsilon_{p}=0, \varepsilon_{d}>0\right)$.

The intuition behind the proposition is transparent from the above argument. Since with the mutual precedential effect the first plaintiff's winning probability $p_{1}$ coincides with the likelihood of an unfavorable precedent being set for the defendant, if $p_{1}$ is sufficiently high (low), the defendant is willing to raise (lower) his offer to avoid (face) trial. If the precedent is nonmutual, this proposition predicts a unilateral result. Under the offensive collateral estoppel, any precedent is unfavorable to the defendant $\left(L_{T}<L_{S}\right)$, so the defendant tries to avoid trial regardless of his winning probability relative to the oneperiod problem. By the same token, under the nonmutual defensive collateral estoppel, the defendant is eager to go to court to establish a favorable precedent for the second period regardless of $p_{1}$.

We next examine how changes in the magnitude of precedential effect influence the parties' settlement incentives. To this end, we again focus on the cost of precedent setting, $L_{\mathrm{T}}-L_{\mathrm{S}}$. Since the increase in pro-plaintiff precedencial value, $\varepsilon_{p}$, makes a pro-plaintiff precedent more unfavorable to the defendant without affecting a pro-defendant precedent, the cost, $L_{T}-L_{S}$, increases with $\varepsilon_{p}$, while the opposite is true for an increase in the prodefendant precedential value $\varepsilon_{d}$. The following proposition follows from this observation.

Proposition 2. (i) The first-period equilibrium settlement probability and offer are increasing (decreasing) in $\varepsilon_{p}\left(\varepsilon_{d}\right)$. Suppose the precedential effect is symmetric (i.e., $\varepsilon_{p}=\varepsilon_{d}=\varepsilon$ ); then (ii) the first-period equilibrium settlement rate and offer are increasing (decreasing) in the simultaneous increase in $\varepsilon_{p}=$ $\varepsilon_{d}=\varepsilon$ if $p_{1}$ is sufficiently high (low); (iii) $\hat{p}_{1}>\frac{1}{2}$ for all $\varepsilon>0$; and (iv) $\hat{p}_{1}$ increases with $\varepsilon$.

The second result is not obvious because it refers to the simultaneous increase in pro-plaintiff and pro-defendant precedential values. The intuition behind the result can be explained as follows. When $p_{1}$ is sufficiently high (the case with sufficiently low $p_{1}$ is analogous), the defendant puts more weight to the pro-plaintiff precedential value, $\varepsilon_{p}$, even if both $\varepsilon_{p}$ and $\varepsilon_{d}$ increase by the same magnitude, since the former is more likely to be realized. Cases (iii) and (iv) concern the behavior of the threshold probability. That the threshold probability is greater than one-half may be surprising given the symmetry of the precedential effect. The implied bias toward trial is due to the fact that the defendant can exploit the option value associated with trial. ${ }^{15}$ Depending on

15. It is useful to interpret $L_{\mathrm{T}}$ as a lottery of taking $L_{\mathrm{w}} \equiv L^{*}(p+\varepsilon)$ and $L_{\mathrm{T}} \equiv L^{*}(p-\varepsilon)$ with probability $p_{1}$ and $\left(1-p_{1}\right)$, respectively. When $p_{1}=\frac{1}{2}, L_{T}$ represents an actuarially fair lottery for a certain loss expected from settlement $\left(L_{s}=L^{*}(p)\right)$. Since $L^{*}$ is concave in $p$, the defendant prefers the actuarially fair lottery of losses to a certain loss. 
the first trial outcome, the defendant will face different prospects to respond in the second period. This creates the option value for the defendant: With variable winning probabilities, he can tailor his settlement offer on each contingency and can do better than when faced with a fixed winning probability. The intuition for the last result is similar.

\section{Further Implications of Correlated Decisions}

\subsection{Front-loading of Litigation Efforts}

When an issue before the court raises broad public interests, there are often intensive efforts on both sides in the initial precedent-setting stage. This is especially true in the so-called landmark cases, which have profound impact on future cases. For example, Roe v. Wade, the 1973 Supreme Court decision that legalized abortion, and Brown v. Board of Education, the 1954 Supreme Court decision that found segregation in public schools unconstitutional, are two such frequently cited cases. As we have witnessed recently, the controversy over a woman's constitutional right to abortion has drawn national attention, and people on both sides of the issue have staged aggressive campaigns to win the court's favor. The underlying force that drives these efforts is the concern over precedents.

To explore this issue within our framework, let us now suppose that each party of litigation can influence the winning probability by undertaking efforts in the two periods. By examining how effort in each period affects the welfare of each party, we can study the relative effectiveness of effort in one period over effort in another period. First, to measure the defendant's first-period incentive for litigation effort, we compute the total derivative of the indirect utility function in [D1] with respect to $p_{1}$. This shows the extent to which a given increase in the winning probability improves the defendant's welfare.

$$
\frac{d L_{1}}{d p_{1}}=\frac{\partial L_{1}}{\partial p_{1}}=\left(1-F\left(\hat{w}_{1}\right)\right)\left(L_{w}-L_{L}\right)+\int_{\hat{w}_{1}}^{\bar{w}} w d F+F\left(\hat{w}_{1}\right) \hat{w}_{1}
$$

Reducing $p_{1}$ has both long-term and short-term effects. The first term of the right-hand side represents the long-term effect, and the remaining two terms represent the short-term effect. The short-term effect captures a direct benefit the defendant receives by improving his winning chance in the first period. The long-term effect measures the expected benefit of setting a favorable precedent.

Similarly, the defendant's second-period incentive for litigation effort can be measured by

$$
\frac{d L_{i}(p)}{d p}=\int_{\hat{w}_{i}}^{\bar{w}} w d F+F\left(\hat{w}_{i}\right) \hat{w}_{i}
$$

depending on the first-period outcome $i=\mathrm{W}, \mathrm{L}$, and S. Notice that the longterm effect is absent in the second period since the defendant has no preceden- 
tial effect to worry about. If these short-term effect terms are not much different, the first-period incentive will be greater than the second-period incentive, due to the precedential effect. Thus, we have the following proposition.

Proposition 3. If either the litigation costs $c+d$ are sufficiently low, or $H^{\prime}(\cdot)>K$ for sufficiently large $K$, then $\frac{d L_{1}(p)}{d p_{1}}>\frac{d L_{i}(p)}{d p}$ for $i=\mathrm{W}, \mathrm{L}$, and $\mathrm{S}$; that is, the first-period effort is more effective than the second-period effort. In addition, if $H^{\prime}(\cdot)>K$ for sufficiently large $K$, the relative effectiveness of the first-period effort over the second-period effort, measured by their marginal rate of substitution, $\frac{d L_{1}(p)}{d p_{1}} / \frac{d L_{i}(p)}{d p}$, increases as the precedential value, $\varepsilon_{p}$ or $\varepsilon_{d}$, increases.

Under the identified circumstances, this proposition confirms a familiar notion that it is more important to set a favorable precedent than to fight against the unfavorable one already set. That an increased precedential effect makes the first-period effort relatively more important is also intuitive. The immediate implication of this proposition is that the defendant is likely to front-load his effort to the initial precedent-setting stage. This will be indeed the case if the defendant faces a standard symmetric, increasing disutility function $D\left(-p_{1},-p_{2}\right)$, associated with his winning probability in each period. If, in addition, the two period efforts are substitutes (i.e., $\left.\frac{\partial^{2} D}{\partial\left(-p_{1}\right) \partial\left(-p_{2}\right)}>0\right)$, the front-loading effect is likely to be acute, since the defendant will try to divert this effort away from the second period into the first period. 16

Several remarks are in order. First, the first condition has an intuitive explanation. In our model, the precedential effect arises only through trial. Since low litigation costs make trial more likely, this implies that setting a good precedent becomes more important when the litigation costs are smaller. Second, the hypotheses of the proposition are sufficient conditions. ${ }^{17}$ Thus, the results may hold even when the conditions are not met. (We conjecture this to be the case for a wide range of parameter values.) Finally, the result of the proposition does not depend on whether the precedential effect is mutual or not. This is because the long-term incentive for the first-period effort depends only on $L_{\mathrm{W}}-L_{\mathrm{L}}$, the second-period welfare difference in winning and losing.

Given the way our model is structured, the front-loading effect does not apply to the plaintiffs. They are essentially myopic and lack the long-term

16. The substitutes case is most relevant when the defendant faces a budget constraint in financing his litigation efforts. Under a fixed budget, for example, the first-period effort can be increased only at the expense of the second-period effort.

17. The condition regarding $H(\cdot)$ is not intuitive. Its purpose is to ensure that an indirect effect through the change in the settlement rates does not dominate the direct effect. 
effort incentives. However, through mutually beneficial contracting, the first plaintiff can be induced to internalize the external benefits she provides to the second plaintiff, as long as the external benefit is positive. Defining an ex ante expected utility of the second plaintiff as $U_{2} \equiv\left(1-F\left(\hat{w}_{1}\right)\right) U_{\mathrm{T}}+F\left(\hat{w}_{1}\right) U_{\mathrm{S}}$, we can measure the external effect as follows:

$\frac{d U_{2}}{d p_{1}}=\left(U_{\mathrm{S}}-U_{\mathrm{T}}\right) f\left(\hat{w}_{1}\right) \frac{d \hat{w}_{1}}{d p_{1}}+\left(1-F\left(\hat{w}_{1}\right)\right)\left[U_{\mathrm{W}}-U_{\mathrm{L}}\right]$

The second term captures the effect of setting a favorable precedent for the second plaintiff. It is always positive. Thus, if the first term is not sufficiently negative, then the first plaintiff's effort has a positive external effect. Recall that $\frac{d \hat{w}_{1}}{d p_{1}}<0$. Therefore, if $p_{1}$ is sufficiently high so that $U_{\mathrm{S}}-U_{\mathrm{T}}<0$, then the first term is positive. If this is true, even the plaintiffs may front-load their efforts. In fact, there are many organizations whose objective is to help finance individual cases that they believe will have large future impacts. They also provide supporting legal arguments as amicus curiae on behalf of a plaintiff whose case has much bearing on precedent setting. ${ }^{18}$ The American Civil Liberties Union (ACLU), Environmental Defense Fund, and the Nader Group are prominent examples of such organizations. 19

\subsection{Effects on Nuisance Suits}

One growing concern in the United States is that too many frivolous suits, or nuisance suits, are brought to courts. Many of these suits are filed by plaintiffs solely to extract settlement offers without strong court cases (see Bebchuk, 1988). A frequently suggested solution to deter such nuisance suits has been the European fee system, under which a losing party pays for all the litigation costs of both parties.

The reason the European fee system may discourage nuisance suits better than the American fee system is because the former is more discriminatory than the latter against plaintiffs with low winning probabilities. In our model, this is represented by the fact that the expected utility of a plaintiff is a steeper function of her winning probability under the European fee system than under the American fee system. Letting $U_{\mathrm{E}}$ denote the expected utility of plaintiffs under the European fee system, it can be easily shown that in our model,

18. We thank Mitch Polinsky for suggesting this example. Amicus curiae means, literally, a friend of the court. A person with strong interest in, or views on, the subject matter of an action may petition the court for permission to file a brief, ostensibly on behalf of a party. Such amicus curiae briefs are commonly filed in appeals concerning matters of a broad public interest. See Black's Law Dictionary.

19. Note that these preemptive efforts could be socially wasteful because both parties' efforts may wash out each other without changing the overall trial outcome. Also note that this idea applies to nonlegal contexts as well. If there is network extermality, or strong path-dependence, initial small investment matters a lot (Arthur, 1987; David, 1984). In this situation, economic agents will try to turn the initial event in their favor, as the battle between VHS and Beta Max graphically shows in the context of the VCR market penetration. 
$U_{\mathrm{E}} \gtreqless U^{*}$ iff $p \gtreqless \frac{d}{c+d} \cdot 20$ (Recall that $U^{*}$ is the expected utility of the plaintiff in the one-period model under the American fee system.)

To illustrate how the two systems differ in their abilities to deter nuisance suits, suppose a plaintiff must incur some fixed costs, $\psi$, such as pre-filing investigation costs, to bring a suit. We assume that these costs are incurred before the plaintiff is informed of her damage. This assumption mainly serves expositional clarity, ${ }^{21}$ but it is not without realism. It will hold if, for example, a victim must have a costly medical examination to assess her injury before filing a suit. Facing some pre-filing costs, plaintiffs with low winning probabilities will not find it attractive to bring suits. Let $p^{\mathrm{E}}(\psi)$ and $p^{\mathrm{A}}(\psi)$ denote threshold probabilities below which plaintiffs will not file suits under the European system and under the American system, respectively. As Figure 1 illustrates,

$$
p^{\mathrm{E}}(\psi)>p^{\mathrm{A}}(\psi) \quad \text { for all } \psi<U^{*}\left(\frac{d}{c+d}\right)
$$

That is, the threshold probability under the European system is greater than that under the American system, which implies that more nuisance suits are deterred under the European fee system, provided that parties' litigation costs do not differ much. This result is consistent with Shavell (1982).

We argue in this section that correlated decisions can exercise similar deterrent effects on nuisance suits. The key observation here is that correlated decisions give the defendant extra incentives to be tougher against a plaintiff with a low winning probability. Recall from Proposition 1 that the defendant makes a smaller settlement offer (than when decisions are not correlated) to the plaintiffs with winning probability less than $\hat{p}_{1} \in\left(\frac{1}{2}, 1\right)$. It easily follows from this that $U_{1}<U^{*}$ iff $p_{1}<\hat{p}_{1}$; that is, the first plaintiff's expected utility is

20. This can be shown by following the usual steps. Under the European fee system, the optimal decision rule of the plaintiff with damage $w$ is to

$$
\text { Accept } s \text { iff } s \geq p w-(1-p)(c+d) \text {. }
$$

Defining $s_{E}(\hat{w})$ as the minimum offer to induce settlement with type $\hat{w}$, the defendant's problem is to solve

$$
L_{\mathrm{E}}(p) \equiv \min _{\hat{w} \geq c / p} s_{\mathrm{E}}(\hat{w}) F(\hat{w})+[1-F(\hat{w})] p(c+d)+p \int_{\hat{w}}^{\tilde{w}} w d F .
$$

Solving [DE] reveals that the settlement behavior is the same under the European fee system as under the American fee system. That is, $\hat{w}_{E}=\hat{w}^{*}$. However, the equilibrium expected utility of the plaintiff, which can be obtained by substituting $\hat{w}_{\mathrm{E}}$ into the ex ante utility function of the plaintiff, is such that $U_{\mathrm{E}}-U^{*}=(c+d) p-d$.

21. If the plaintiff learns her damage before incurring the pre-filing costs, then the plaintiff's suing decision can have a signaling effect on the defendant, because different types of plaintiffs may react to the given fixed costs differently. In general, equilibrium under this specification involves mixed strategies where the plaintiff (with different types) randomizes between suing and not suing. 


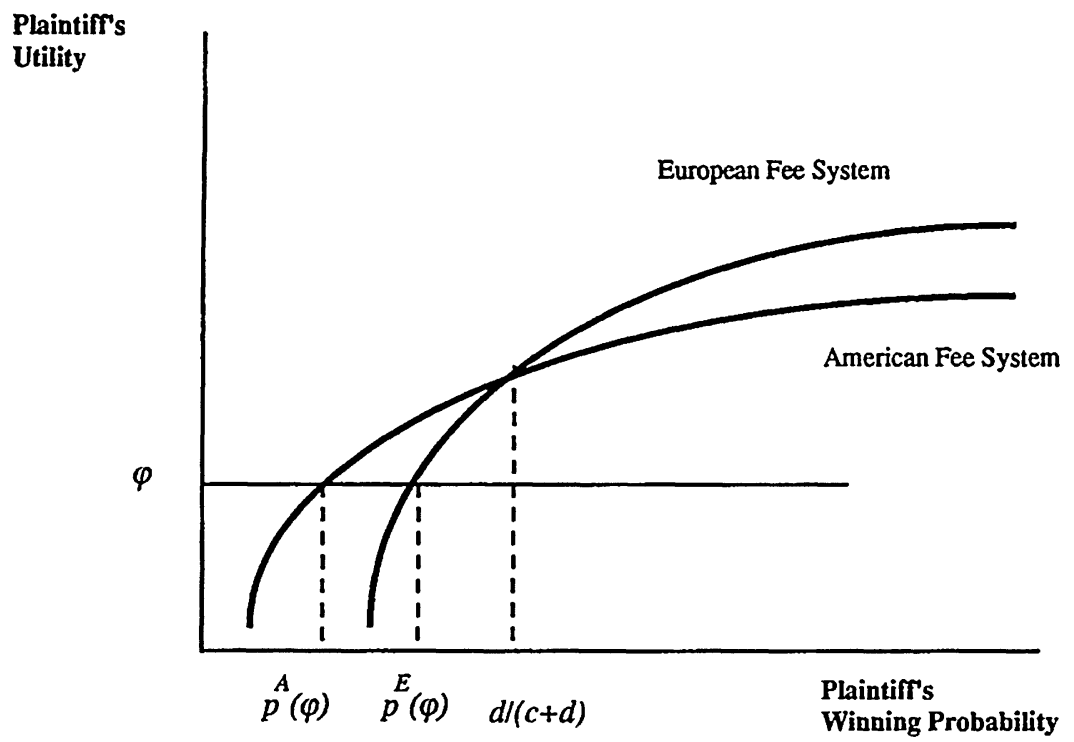

Figure 1. Threshold probabilities of filing suit under different attorney fee systems

less with correlated decisions than without if the plaintiff's winning probability is less than $\hat{p}_{1}$. This, in turn, implies that

$p^{\mathrm{CD}}(\psi)>p(\psi)^{\mathrm{A}} \quad$ for all $\psi<U^{*}\left(\hat{p}_{1}\right)$

where $p^{\mathrm{CD}}$ denotes the minimum winning probability that the first plaintiff brings a suit under correlated decisions. From this, we can draw the following conclusion.

Proposition 4. Symmetric or nonmutual defensive collateral estoppel deters nuisance suits, while nonmutual offensive collateral estoppel encourages nuisance suits.

This proposition is a direct result of applying Propositions 1 and 2. If the precedential effect is symmetric or favorable to the defendant, we know that the threshold probability, $\hat{p}_{1}$, is greater than one-half (unity in the case of defensive collateral estoppel); hence precedents deter more lawsuits whose winning probabilities are less than one-half. On the other hand, under the nonmutual offensive collateral esteppol, the threshold probability is zero; hence, nuisance suits are encouraged relative to a case without precedents.

This suggests that common law courts under the American fee system may mimic the performance of the European fee system in deterring nuisance suits, unless the precedential effect is unilaterally in favor of the plaintiffs. The intuition is basically the same: Like the European fee system, correlated decisions tend to discriminate against a plaintiff with a low winning proba- 
bility. The mechanism of discrimination, however, is different. Under correlated decisions, it is implemented by differing attitudes of the defendant toward plaintiffs with different winning probabilities: The defendant is more aggressive in going to trial against the plaintiff with a lower winning probability in order to set a favorable precedent. ${ }^{22}$

\section{Numerical Example}

In this section, we present some numerical examples. The purpose of our numerical exercise is to see (i) how a settlement probability changes as $p_{1}$ increases at any given $\varepsilon$; and (ii) whether the American fee system with correlated decisions can perform as well as the European system. In our simulation, $w$ is uniformly distributed with $f=1 / \overline{\mathrm{w}}$, and $\overline{\mathrm{w}}=200$, and $c=d$ $=10$. In our first example, the size of $\varepsilon$ varies from 0.1 to 0.3 .

Figure 2 largely confirms the finding of Proposition 1 . There is a threshold level of $\hat{p}_{1}$ slightly above 0.5 such that correlated decisions make settlement more (less) likely when the first plaintiff's winning probability is higher (lower) than $\hat{p}_{1}$. Figure 2 also shows that the precedential effect $\varepsilon$ reinforces this effect on the settlement rate.

Figure 3 illustrates that the $U_{\mathrm{E}}$ curve is steeper than the $U^{*}$ curve and crosses at $p_{1}=\frac{d}{c+d}=0.5$. When the precedential value is set at $\varepsilon=0.3$, the American fee system tracks almost perfectly the European fee system in terms of the first plaintiff's expected utility in the low range of $p_{1}$. Moreover, when $p_{1}$ is high, the plaintiff's expected utility is greater under the American fee system with correlated decisions than under the European fee system. This suggests that in the context of repeated litigation the American fee system might be more efficient because while low-probability cases are eliminated to the same extent, meritorious claims do better under the American fee system.

\section{Correlated Damages}

This section analyzes the effects of correlated damages on the litigants' settlement behavior. As mentioned earlier, in factually similar cases, judgment awards tend to be correlated across periods, even though a prior court's damage awards do not have any legally binding effect. ${ }^{23}$ This is especially true when damages are correlated across cases, since court judgments are likely to reflect the correlated damages. In this situation, the initial court action can reveal some information that the defendant (who is uninformed about the actual damages) may find useful in inferring the future plaintiffs' damages. A successful inference about future cases helps the defendant to

22. This is not to suggest that precedents can replace the European fee system in deterring nuisance suits. For one thing, the deterrence effect of precedents is relevant only in a repeatedlitigation situation.

23. The fact that courts are not bound by prior judgment awards distinguishes this situation from the correlated decisions. 


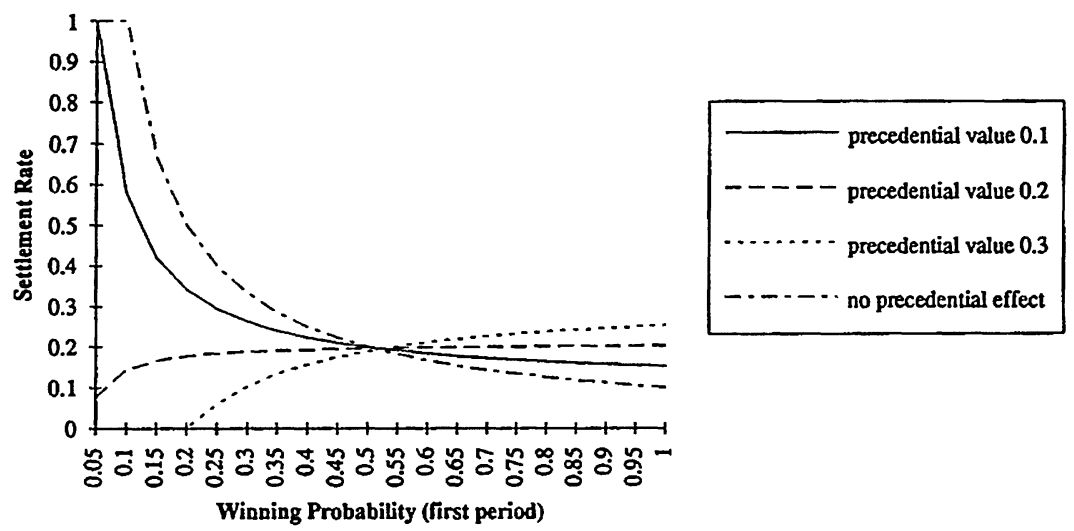

Figure 2. Settlement Rates with Different Precedent Values

make more tailored settlement offers and thereby reduce his expected loss. Court proceedings can reveal information in several ways. The defendant can learn directly from an actual award. Learning can take place, however, even when the case is settled out of court, as plaintiffs' acceptance/rejection decisions reveal the strength of their cases. In this section, we study the ways in which various learning opportunities available from an initial court action affect the defendant's incentives for settlement.

We consider a slightly modified model in which the second plaintiff's damage, $w_{2}$, is positively correlated with the first plaintiff's damage, $w_{1}$. Liabilities are no longer correlated; that is, plaintiffs in both periods are assumed to have the same winning probability $p$. Assume first that $w_{2}$ is distributed over the same support as $w_{1}$ according to a conditional distribution function $G\left(w_{2} \mid w_{1}\right)$, with its probability density function $g\left(w_{2} \mid w_{1}\right)$. The following assumptions modify our original hazard rate condition to a new distribution and conceptualize a correlation relationship between $w_{2}$ and $w_{1}$ :

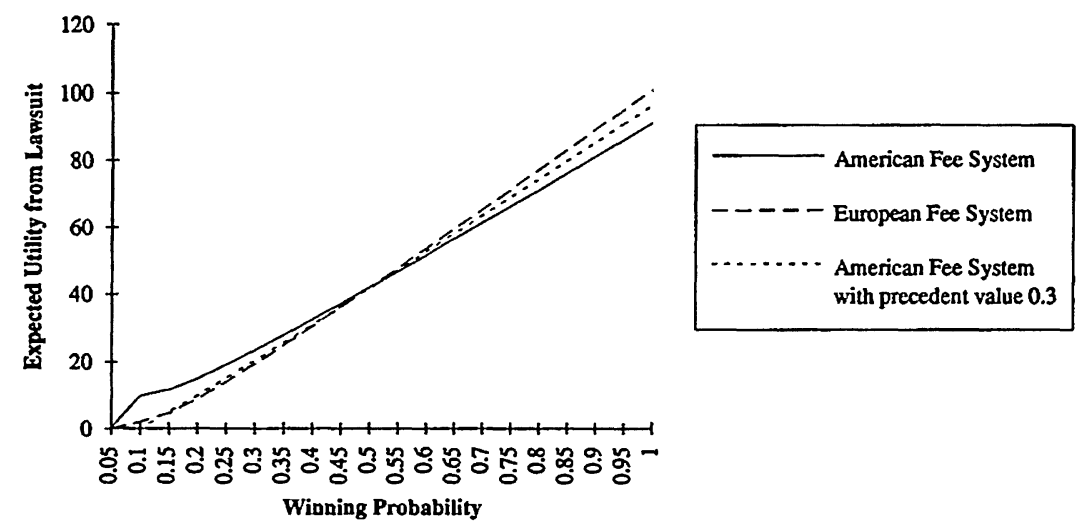

Figure 3. Precedential Effect and the European Fee System 


$$
k\left(w_{2} \mid w_{1}\right) \equiv \frac{G\left(w_{2} \mid w_{1}\right)}{g\left(w_{2} \mid w_{1}\right)} \text { is increasing in } w_{2} \text { for all } w_{1} .
$$

$$
\text { (Monotone Likelihood Ratio Property) } \frac{g\left(w_{2} \mid y\right)}{g\left(w_{2} \mid x\right)} \text { is increasing }
$$
in $w_{2}$ for all $y>x$.

The monotone likelihood ratio property establishes $w_{1}$ as a monotonic signal about $w_{2}$ (Milgrom, 1981). According to this property, that the first plaintiff has a high damage is an informative indication that the second plaintiff also has a high damage. In our context, this assumption implies that $k\left(w_{2} \mid w_{1}\right)$ is decreasing in $w_{1}$.

Lemma 2. [A2] implies $\frac{\partial k}{\partial w_{1}}<0$.

Recall our notational convention under which $\hat{w}_{1}$ denotes the first-period threshold type of the plaintiff, and $\hat{w}_{s}, \hat{w}_{L}, \hat{w}_{w}$ denote the second-period threshold types given that the first-period outcomes are $\mathrm{S}, \mathrm{L}$, and $\mathrm{W}$, respectively. As before, corresponding settlement offers are defined as $s\left(\hat{w}_{\mathrm{i}}\right)=\hat{w}_{i} p$ $-c$ for $i=1, \mathrm{~S}, \mathrm{~L}, \mathrm{~W}$. Again we start backwards. Consider the second period first. Suppose that the first case was settled. Then, the defendant can infer that the first-period damage is less than $\hat{w}_{1}$. On the other hand, if the first case had gone to court and the defendant won the trial, then he learns that the firstperiod damage is greater than $\hat{w}_{1}$. However, had the defendant lost the trial, the actual damage in the first period, $w_{1}$, is revealed through the judgment award by the first court. In the second period, the defendant will tailor his settlement offer based on this inferred information about the first-period damage. Since $\hat{w}_{1}$ summarizes all the necessary information in the first two cases, we can write $\hat{w}_{i}\left(\hat{w}_{1}\right)$ and $s_{i}\left(\hat{w}_{1}\right)$ to denote the defendant's second-period threshold type and offer, when the first-period outcome is indicated by $i=\mathrm{S}, \mathrm{L}$. Lastly, $\hat{w}_{\mathrm{W}}\left(w_{1}\right)$ and $s_{\mathrm{W}}\left(w_{1}\right)$ are used for the case where the plaintiff won the first trial.

Proposition 5. With [A1'] and [A2], (i) $\hat{w}_{\mathrm{W}}(\cdot)$ and $s_{\mathrm{W}}(\cdot)$ are increasing in $w_{1}$; (ii) $\hat{w}_{\mathrm{S}}\left(\hat{w}_{1}\right)<\hat{w}_{\mathrm{W}}\left(\hat{w}_{1}\right)<\hat{w}_{\mathrm{L}}\left(\hat{w}_{1}\right) ;$ (iii) $s_{\mathrm{S}}\left(\hat{w}_{1}\right)<s_{\mathrm{W}}\left(\hat{w}_{1}\right)<s_{\mathrm{L}}\left(\hat{w}_{1}\right)$.

These results characterize the way in which the defendant pegs the settlement offer on the first-period outcome. First, the defendant lowers the settlement offer if the first case was settled, since it would imply that $w_{1} \in\left[0, \hat{w}_{1}\right]$. Second, the defendant raises the offer if there was a trial and he won, since it would then imply that $w_{1} \in\left[\hat{w}_{1}, \bar{w}\right]$. Lastly, if the defendant lost the trial, he tailors the offer on the actual first-period damage $w_{1}$. Obviously, this offer would be greater than $s_{S}\left(\hat{w}_{1}\right)$. In general, the defendant makes a higher offer after a trial than after a settlement. Note that this does not necessarily make 
the defendant want to settle in the first period. Raising the first-period settlement offer reduces the probability of going to trial, but when the case actually goes to trial, this will adjust the defendant's belief about the second plaintiff's damage even more upwardly, resulting in an even higher equilibrium offer in the second period. In fact, the only reason for the defendant to change his settlement offer comes from his learning motive. Because of the different ways in which the settlement and trial reveal information to the defendant, the defendant will adjust his settlement offer in a way that makes the most of his learning opportunities.

This intuition becomes clear in the defendant's first-period problem. As in the case of correlated decisions, the defendant's first-period decision reflects his concerns about the resulting impacts on his second-period litigation. Let $L_{\mathrm{S}}\left(\hat{w}_{1}\right), L_{\mathrm{L}}\left(\hat{w}_{1}\right)$, and $L_{\mathrm{W}}\left(w_{1}\right)$ denote the defendant's (minimized) second-period loss when his first period offer, $s\left(\hat{w}_{1}\right)$, resulted in outcomes, S, L, and W, respectively. These succinctly summarize the second-period consequences of offering $s\left(\hat{w}_{1}\right)$. Now, the defendant's first-period problem can be represented as

[D2]

$$
\begin{aligned}
L_{1}(p)= & \min _{\hat{w}_{1} \geq c / p}\left(s\left(\hat{w}_{1}\right)+L_{\mathrm{S}}\left(\hat{w}_{1}\right)\right) F\left(\hat{w}_{1}\right)+\left(1-F\left(\hat{w}_{1}\right)\right) \\
& \times\left[d+(1-p) L_{\mathrm{L}}\left(\hat{w}_{1}\right)\right]+p \int_{\hat{w}_{1}}^{\bar{w}}\left(w+L_{\mathrm{W}}(w)\right) d F(w) .
\end{aligned}
$$

The first-order condition for an interior solution to [D2] is given by

$H\left(\hat{w}_{1}\right)=\frac{c+d+\bar{L}_{\mathrm{T}}\left(\hat{w}_{1}\right)-\bar{L}_{\mathrm{S}}\left(\hat{w}_{1}\right)}{p}$,

where $\bar{L}_{\mathrm{T}}\left(\hat{w}_{\mathrm{T}}\right)=p \bar{L}_{\mathrm{W}}\left(\hat{w}_{1}\right)+(1-p) \bar{L}_{\mathrm{L}}\left(\hat{w}_{1}\right)$, and $\bar{L}_{\mathrm{i}}\left(\hat{w}_{1}\right)$ denotes the defendant's second-period loss following the outcome $i(=\mathrm{L}, \mathrm{W}, \mathrm{S})$, when the first plaintiff's actual type is $\hat{w}_{1}$. Here, the bias term, $\bar{L}_{\mathrm{T}}\left(\hat{w}_{1}\right)-\bar{L}_{\mathrm{S}}\left(\hat{w}_{1}\right)$, can be interpreted as the marginal learning benefit associated with increasing a settlement offer slightly. Consider that the defendant increases his offer slightly and induces more settlement at the margin. The marginal type $\hat{w}_{1}$, who would have gone to trial before, now settles as a result of the increase in the offer. Note however that settlement does not enable the defendant to recognize the marginal type, $\hat{w}_{1}$, precisely; instead, the marginal type is regarded as one of many inframarginal types, $\left[0, \hat{w}_{1}\right]$, that could have settled. So, the marginal type is underestimated in the defendant's offer decision. Because of this, the defendant fails to attain the minimum second-period loss with respect to the marginal type. Similarly, the defendant overestimates the marginal type when he goes to trial and wins the case. Only when the defendant goes to trial and loses to the marginal type is the marginal type correctly recognized, and the defendant attains the minimum loss. Thus, $\bar{L}_{\mathrm{W}}\left(\hat{w}_{1}\right)<\min \left\{\bar{L}_{\mathrm{S}}\left(\hat{w}_{1}\right)\right.$, 
$\left.\bar{L}_{\mathrm{L}}\left(\hat{w}_{1}\right)\right\}$; that is, losing a trial offers a learning benefit to the defendant in terms of the second-period loss.

From this follows the next proposition.

Proposition 6. Assume [A1'] and [A2]. The first-period settlement rate and settlement offer are smaller with correlated damages than without, if the litigation costs $c+d$ are sufficiently high or if $p>\tilde{p}$ or $p<\check{p}$ for some $\tilde{p}, \check{p} \in$ $(0,1)$.

Note that $\bar{p}$ can be smaller than $\check{p}$; that is, the result may hold for the entire types of the first plaintiff. So, the bias against settlement may be robust. Proposition 5 identifies several reasons why the defendant may learn more from trial than from settlement. One is the defendant's losing probability at the first trial. Since losing at trial reveals precise information about the first plaintiff's damage, the more likely the defendant is to lose at the trial the more likely he is to learn from trial. This is not to say that the defendant values the likelihood of losing at trial. It only suggests that he values the learning component of losing; that is, he favors trial relatively more than he otherwise would without correlated damages. The other determining force is the relative likelihood of settlement to trial. As settlement becomes more likely (for example, as the result of an increase in $c+d$ or a decrease in $p$ ), settlement becomes less valuable in providing informative signals about the second plaintiff's damage. In general, the proposition predicts a learning bias in favor of trial.

Two comments are warranted in interpreting this result. First, in this section we have focused only on the effect of correlated damages. If the effect of correlated decisions is also present, the analyses in the previous section imply that the trial bias may be weakened. This is especially likely when the first plaintiff's winning probability is very high so that correlated decisions alone tend to encourage settlement (recall Proposition 1). Second, while disputing parties may care about learning, trial is not the only way to learn about judgment. In practice, lawyers often hire private citizens as mock jurors to test their expected judgment and to make a better inference about the awards. This is especially relevant in cases where juries rather than judges make the awards and in cases where litigation is not repeated so that parties cannot learn from previous trial.

\section{Concluding Remarks}

We have examined the role of precedents in repeated litigation. Identifying correlated decisions and correlated damages as two forms of precedents, we have shown first that the defendant is more willing to settle when an unfavorable precedent is more likely to be set, resulting in a higher settlement rate. Second, the parties will engage in preemptive campaigns to turn the precedent in their favor, which could be socially wasteful. Third, like the European fee system, the existence of precedents tends to penalize plaintiffs with low winning probabilities and discourage nuisance suits. Lastly, correlated dam- 
age awards provide a valuable learning opportunity to the defendant, allowing him to make a more tailored offer after experiencing an initial trial.

Several further remarks are relevant for our research.

What if the Plaintiff is a Repeat Player? Although our model has dealt with civil litigation in which the defendant is the only repeat player, our results do not depend on this particular setting. Consider the case where either the plaintiff or both parties are repeat players. ${ }^{24}$ Since an initial court decision has long-term effects, it still remains true that the repeat player will try to avoid litigation whenever an unfavorable precedent is likely to be set in an early stage. Note that our results are also applicable to criminal actions. Government prosecutors often take similar criminal cases, and thus, as repeat players, they have an interest in setting favorable precedents. The upshot is that the concern over precedent induces a repeat player to deviate from a shortterm best strategy.

Asymmetric Precedential Effect. Current debates over precedents have centered on the issue of fairness, that is, whether abdication of mutuality has led to an unfair outcome for one party. Our findings appear to support this view: A nonmutual precedential effect does favor one party at the expense of the other party's welfare. Also, as in Note (1992), the initial plaintiff can take advantage of the offensive collateral estoppel by extorting the defendant through higher settlement. Our analysis renders additional support to the symmetric precedent from a different perspective. According to our analysis, a symmetric precedent can provide additional benefit of deterring nuisance suits; while a precedent unilaterally adversarial to the defendant can encourage nuisance suits.

Whom to sue? When to sue? We have examined how concerns over precedents affect a repeat player's pretrial bargaining strategy. Precedential concerns can also have other interesting strategic implications. First, it can affect a repeat player's decision as to whom to litigate first. In light of our analysis, it is not hard to imagine that the repeat player would try to litigate the weakest opponent first. By confronting the weakest opponent first, he can easily establish a favorable precedent, which will put him in a better position to deal with stronger opponents later. Also, a plaintiff's decision as to when to sue can be affected by a precedential concern. If she has a good prospect of winning the case, she may postpone filing a suit until after an even more favorable precedent is set. On the other hand, if the prior assessment is not favorable, she might want to rush for a suit; since the chances will be even worse after other plaintiffs set bad precedents.

\section{Appendix}

Proof of Lemma 1. Case (i) is obvious from the first-order condition, and (ii) follows from $L$ being an increasing function of $p$ and from the envelope theorem.

24. Plaintiff is a repeat player, for example, in a landlord-tenant, or bank-debtor relationship. In a manufacturer-supplier, or labor union-company relationship, both parties are repeat players. 
Proof of Proposition 1. It suffices to show that $\hat{w}_{1} \geq \hat{w}^{*}$ iff $p_{1} \geq \hat{p}_{1}$ for some $\hat{p}_{1} \in(0,1)$. Since $L_{\mathrm{T}}$ is continuous and increasing in $p_{1}$, while $L_{S}$ is independent of $p_{1}$, and from Corollary 1 and [A1], there exists such $\hat{p}$. From this, it naturally follows that $s\left(\hat{w}_{1}\right) \geq s\left(\hat{w}^{*}\right)$ iff $p_{1} \geq \hat{p}_{1}$. The nonmutual cases are obvious. For example, when $\varepsilon_{p}>0, \varepsilon_{d}=0, L_{\mathrm{T}} \leq L_{\mathrm{S}}$ for all $p_{1} \in[0,1]$. Thus, $\hat{p}_{1}=0$.

Proof of Proposition 2. Case (i) is obvious from the preceding argument in the text; (ii) is true since for sufficiently high (low) $p_{1}, L_{\mathrm{T}}-L_{\mathrm{S}}$ is increasing (decreasing) in $\varepsilon$.

To prove (iii), it suffices to show that $L_{\mathrm{T}}\left(\varepsilon, p_{1}\right)-L_{\mathrm{S}}<0$ for all $\varepsilon>0$ if $p_{1}$ $\leq \frac{1}{2}$. Since $0<\frac{d L_{\mathrm{W}}}{d \varepsilon}<-\frac{d L_{\mathrm{L}}}{d \varepsilon}$ if $\varepsilon>0$, and $0<\frac{d L_{\mathrm{W}}}{d \varepsilon}=-\frac{d L_{\mathrm{L}}}{d \varepsilon}$ if $\varepsilon=0$, for all $\varepsilon>0, \quad \frac{d L_{\mathrm{T}}}{d \varepsilon}=p_{1} \frac{d L_{\mathrm{W}}}{d \varepsilon}+\left(1-p_{1}\right) \frac{d L_{\mathrm{L}}}{d \varepsilon}<0 \quad$ if $p_{1} \leq \frac{1}{2}$.

Since $L_{\mathrm{T}}\left(0, p_{1}\right)=L_{\mathrm{S}}$ for all $\varepsilon>0$, if $p_{1} \leq \frac{1}{2}$, $L_{\mathrm{T}}\left(\varepsilon, p_{1}\right)-L_{\mathrm{S}}=\int_{0}^{\varepsilon} \frac{d L_{\mathrm{T}}\left(\tilde{\varepsilon}, p_{1}\right)}{d \tilde{\varepsilon}} d \tilde{\varepsilon}<0$

To prove (ii), consider $\varepsilon<\varepsilon^{\prime}$. Let $\hat{p}_{1}=\hat{p}_{1}(\varepsilon)$, and $\hat{p}_{1}^{\prime}=\hat{p}_{1}\left(\varepsilon^{\prime}\right)$. We show that $\hat{p}_{1}<\hat{p}_{1}^{\prime}$.

First, note that (a) $\left.\frac{d L_{\mathrm{T}}}{d \varepsilon}\right|_{\varepsilon=0}>0$ if $p_{1}>\frac{1}{2}$; (b) $\frac{d^{2} L_{\mathrm{T}}}{d \varepsilon^{2}}<0$; and (c) $\frac{d^{2} L_{\mathrm{T}}}{d \varepsilon d p_{1}}$ $=\frac{d\left(L_{\mathrm{W}}-L_{\mathrm{L}}\right)}{d \varepsilon}>0$. From (a) and (b),

$$
\frac{d L_{\mathrm{T}}\left(\tilde{\varepsilon}, \hat{p}_{1}\right)}{d \bar{\varepsilon}}<0 \quad \text { for all } \tilde{\varepsilon}>\varepsilon
$$

Otherwise, $L_{\mathrm{T}}\left(\varepsilon, \hat{p}_{1}\right)-L_{\mathrm{S}}>0$, contrary to the definition of $\hat{p}_{1}$.

Now suppose that $\hat{p}_{1} \geq \hat{p}_{1}^{\prime}$. Then,

$$
\begin{aligned}
L_{\mathrm{T}}\left(\varepsilon^{\prime}, \hat{p}_{1}^{\prime}\right)-L_{\mathrm{S}} & =\int_{0}^{\varepsilon^{\prime}} \frac{d L_{\mathrm{T}}\left(\tilde{\varepsilon}, \hat{p}_{1}^{\prime}\right)}{d \tilde{\varepsilon}} d \tilde{\varepsilon} \\
& \leq \int_{0}^{\varepsilon^{\prime}} \frac{d L_{\mathrm{T}}\left(\tilde{\varepsilon}, \hat{p}_{1}\right)}{d \tilde{\varepsilon}} d \tilde{\varepsilon} \quad \text { by (c) } \\
& =\int_{0}^{\varepsilon} \frac{d L_{\mathrm{T}}\left(\bar{\varepsilon}, \hat{p}_{1}\right)}{d \tilde{\varepsilon}} d \bar{\varepsilon}+\int_{\varepsilon}^{\varepsilon^{\prime}} \frac{d L_{\mathrm{T}}\left(\tilde{\varepsilon}, \hat{p}_{1}\right)}{d \tilde{\varepsilon}} d \tilde{\varepsilon}
\end{aligned}
$$




$$
\begin{aligned}
& =L_{\mathrm{T}}\left(\varepsilon, \hat{p}_{1}\right)-L_{\mathrm{S}}+\int_{\varepsilon}^{\varepsilon^{\prime}} \frac{d L_{\mathrm{T}}\left(\tilde{\varepsilon}, \hat{p}_{1}\right)}{d \tilde{\varepsilon}} d \tilde{\varepsilon} \\
& <0,
\end{aligned}
$$

which contradicts the definition of $\hat{p}_{1}^{\prime}$. The last inequality follows from the hypothesis and (d).

Proof of Proposition 3. For the first part of the proposition, it suffices to show that

$\frac{d L_{1}}{d p_{1}}>\frac{d L_{i}}{d p} \quad$ for $i=\mathrm{W}, \mathrm{L}, \mathrm{S}$

Through some algebraic manipulation, we can write the difference of the two terms as follows:

$$
\begin{aligned}
\frac{d L_{1}}{d p_{1}}-\frac{d L_{i}}{d p}= & \left(1-F\left(\hat{w}_{1}\right)\right)\left(L_{\mathrm{W}}-L_{\mathrm{L}}\right)+\int_{\hat{w}_{1}}^{\dot{w}} w d F+F\left(\hat{w}_{1}\right) \hat{w}_{1} \\
& -\left[\int_{\hat{w}_{i}}^{\bar{w}} w d F+F\left(\hat{w}_{i}\right) \hat{w}_{i}\right] \\
= & \left(1-F\left(\hat{w}_{1}\right)\right)\left(L_{\mathrm{W}}-L_{\mathrm{L}}\right)+\int_{\hat{w}_{i}}^{\tilde{w}_{1}} F(w) d w .
\end{aligned}
$$

First, observe that as $c+d$ goes to zero, $\hat{w}_{i}$ goes to zero for all $i=\mathrm{W}, \mathrm{L}, \mathrm{S}$. Since, for any $c+d, \hat{w}_{1} \geq 0$, the second term of the last line can be made arbitrarily small by taking a sufficiently small $c+d$. Since the first term is strictly positive and bounded away from zero, the proof is complete. Next, we show that when $H^{\prime}>K$ for sufficiently high $K, \hat{w}_{1}$ can be made arbitrarily close to $\hat{w}_{i}$ for $i=\mathrm{W}, \mathrm{L}, \mathrm{S}$. Letting $x \equiv \frac{c+d}{p}$, we can write $\hat{w}_{\mathrm{S}}=H^{-1}(x)$. $\left(H^{-1}\right.$ exists because of [A1].) Now, for some $\hat{x} \in\left[x, x+\frac{L_{T}-L_{S}}{p}\right]$,

$$
\begin{aligned}
\hat{w}_{1} & =H^{-1}\left(x+\frac{L_{\mathrm{T}}-L_{\mathrm{S}}}{p}\right) \\
& =\hat{w}_{\mathrm{S}}+\frac{1}{H^{\prime}(\hat{x})}\left(\frac{L_{\mathrm{T}}-L_{\mathrm{S}}}{p}\right),
\end{aligned}
$$

which implies that $\left|\hat{w}_{1}-\hat{w}_{S}\right|<\frac{1}{K}\left(\frac{L_{T}-L_{S}}{p}\right)$. Similarly, one can show that 
$\left|\hat{w}_{\mathrm{S}}-\hat{w}_{i}\right|<\frac{1}{K}\left(\frac{\varepsilon_{m}(c+d)}{p\left(p-\varepsilon_{m}\right)}\right)$ for $\varepsilon_{m}=\max \left\{\varepsilon_{p}, \varepsilon_{d}\right\}$ and $i=\mathrm{W}, \mathrm{L}$. Therefore, by increasing $K, \hat{w}_{1}$ can be made arbitrarily close to $\hat{w}_{i}$ for $i=\mathrm{S}, \mathrm{W}, \mathrm{L}$. This makes the second term in (A1) arbitrarily small. Since the first term of (A1) is positive and bounded away from zero, the whole expression is positive, as desired.

Finally, to prove the last statement, consider the marginal substitution of efforts:

$\frac{\frac{d L_{1}(p)}{d p_{1}}}{\frac{d L_{i}(p)}{d p}}=\frac{\left(1-F\left(\hat{w}_{1}\right)\right)\left(L_{\mathrm{W}}-L_{\mathrm{L}}\right)}{\int_{\hat{w}_{i}}^{\tilde{w}} F(w) d w}+\frac{\int_{\hat{w}_{1}}^{\tilde{w}} F(w) d w}{\int_{\hat{w}_{i}}^{\tilde{w}} F(w) d w}$.

For sufficiently large $K$, the denominator of the first term and the second term remain almost unchanged as $\varepsilon_{p}$ or $\varepsilon_{d}$ increases because $\hat{w}_{i}$ remains relatively unaffected. However, the numerator of the first term strictly increases as $\varepsilon_{p}$ or $\varepsilon_{d}$ increases. Therefore, the marginal rate of substitution increases for sufficiently large $K$.

Proof of Lemma 2. It suffices to show that if $\frac{g(b \mid y)}{g(b \mid x)}>\frac{g(a \mid y)}{g(a \mid x)}$ for all $b>a$, $y>x$, then $k\left(w_{2} \mid y\right)<k\left(w_{2} \mid x\right)$ for all $y>x$ and $w_{2} \in[0, \bar{w}]$.

$$
\begin{aligned}
k\left(w_{2} \mid y\right) & =\frac{\int_{0}^{w_{2}} g(w \mid y) d w}{g\left(w_{2} \mid y\right)} \\
& <\frac{\int_{0}^{w_{2}}\left[g(w \mid x) g\left(w_{2} \mid y\right) / g\left(w_{2} \mid x\right)\right] d w}{g\left(w_{2} \mid y\right)} \\
& =\frac{\int_{0}^{w_{2}} g(w \mid x) d w}{g\left(w_{2} \mid x\right)} \\
& =k\left(w_{2} \mid x\right) .
\end{aligned}
$$

The inequality is due to the monotone likelihood ratio property.

Proof of Proposition 5. Without loss of generality, we can write the defendant's program when there was a settlement in the first period as 
[DS]

$$
\begin{aligned}
& \min _{\hat{w}_{S}} L_{S}\left(\hat{w}_{S} ; \hat{w}_{1}\right)=\frac{1}{F\left(\hat{w}_{1}\right)} \int_{0}^{\hat{w}_{1}}\left[\left(p \hat{w}_{S}-c\right) G\left(\hat{w}_{S} \mid w_{1}\right)\right. \\
& \left.+d\left(1-G\left(\hat{w}_{S} \mid w_{1}\right)\right)+p \int_{\hat{w}_{S}}^{\tilde{w}} w d G\left(w \mid w_{1}\right)\right] d F\left(w_{1}\right) .
\end{aligned}
$$

Therefore, we have first-order condition (FOC):

$$
\frac{\partial L_{S}}{\partial \hat{w}_{S}}=\frac{1}{F\left(\hat{w}_{1}\right)} p \int_{0}^{\hat{w}_{t}} g\left(\hat{w}_{S} \mid w_{1}\right)\left[k\left(\hat{w}_{S} \mid w_{1}\right)-\frac{c+d}{p}\right] d F .
$$

Analogously, the defendant's program when the first plaintiff lost trial is to solve:

[DL]

$$
\begin{aligned}
& \min _{\hat{w}_{L}} L_{L}\left(\hat{w}_{L} ; \hat{w}_{1}\right)=\frac{1}{1-F\left(\hat{w}_{1}\right)} \int_{\hat{w}_{1}}^{\tilde{w}}\left[\left(p \hat{w}_{L}-c\right) G\left(\hat{w}_{L} \mid w_{1}\right)+\right. \\
& \left.d\left(1-G\left(\hat{w}_{L} \mid w_{1}\right)\right)+p \int_{\hat{w}_{L}}^{\tilde{w}} w d G\left(w \mid w_{1}\right)\right] d F\left(w_{1}\right) .
\end{aligned}
$$

Then, its FOC is

$$
\frac{\partial L_{\mathrm{L}}}{\partial \hat{w}_{\mathrm{L}}}=\frac{1}{1-F\left(\hat{w}_{1}\right)} p \int_{\hat{w}_{\mathrm{l}}}^{\bar{w}} g\left(\hat{w}_{\mathrm{L}} \mid w_{1}\right)\left[k\left(\hat{w}_{\mathrm{L}} \mid w_{1}\right)-\frac{c+d}{p}\right] d F .
$$

But if there was a trial and plaintiff 1 won, the defendant's program is to solve for all $w_{1} \in\left[\hat{w}_{1}, \bar{w}\right]$ :

$$
\begin{aligned}
& \text { [DW] } \quad \min _{\hat{w}_{\mathrm{W}}} L_{\mathrm{W}}\left(\hat{w}_{\mathrm{W}} ; w_{1}\right)=\left(p \hat{w}_{\mathrm{W}}-c\right) G\left(\hat{w}_{\mathrm{W}} \mid w_{1}\right) \\
& +d\left(1-G\left(\hat{w}_{\mathrm{W}} \mid w_{1}\right)\right)+p \int_{\hat{w}_{\mathrm{W}}}^{\tilde{w}} w d G\left(w \mid w_{1}\right) .
\end{aligned}
$$

Then, its FOC is

$$
\frac{\partial L_{\mathrm{W}}}{\partial \hat{w}_{\mathrm{W}}}=p g\left(\hat{w}_{\mathrm{W}} \mid w_{1}\right)\left[k\left(\hat{w}_{\mathrm{W}} \mid w_{1}\right)-\frac{c+d}{p}\right] .
$$


Now we can prove (i) by inspecting the above equation. Let $k\left(\hat{w}_{\mathrm{W}} \mid w_{1}\right)=$ $\frac{c+d}{p}$. Then by [A2], $k$ is decreasing in $w_{1}$. Therefore, $\hat{w}_{\mathrm{W}}$ should be increasing in $w_{1}$, that is, $\hat{w}_{\mathrm{W}}^{\prime}\left(\mathrm{w}_{1}\right)>0$, which implies $s_{\mathrm{W}}^{\prime}\left(w_{1}\right)>0$ since $s_{\mathrm{W}}=p \hat{w}_{\mathrm{W}}-c$.

To prove (ii), suppose $\hat{w}_{\mathrm{S}}\left(\hat{w}_{1}\right) \geq \hat{w}_{\mathrm{W}}\left(\hat{w}_{1}\right)$. Then $k\left(\hat{w}_{\mathrm{S}} \mid \hat{w}_{1}\right) \geq \frac{c+d}{p}$. Then,

$$
\frac{\partial L_{S}}{\partial \hat{w}_{S}}=\frac{1}{F\left(\hat{w}_{1}\right)} p \int_{0}^{\hat{w}_{1}} g\left(\hat{w}_{S} \mid w_{1}\right)\left[k\left(\hat{w}_{S} \mid w_{1}\right)-\frac{c+d}{p}\right] d F>0 .
$$

This is a contradiction. Therefore, $\hat{w}_{\mathrm{S}}\left(\hat{w}_{1}\right)<\hat{w}_{\mathrm{W}}\left(\hat{w}_{1}\right)$, which implies that $s_{S}\left(\hat{w}_{1}\right)<s_{\mathrm{W}}\left(\hat{w}_{1}\right)$. Other results follow similarly.

Proof of Proposition 6. The proof involving the condition about $p$ is presented first. It suffices to show that there exists $\tilde{p}, \check{p} \in[0,1]$ such that for $p>$ $\bar{p}$ or $p<\check{p}, \hat{w}_{1}<w^{*}$ and $s\left(\hat{w}_{1}\right)<s^{*}$. Since we know that $\bar{L}_{\mathrm{W}}\left(\hat{w}_{1}\right)<\bar{L}_{\mathrm{S}}\left(\hat{w}_{1}\right)$ for all $p \in[0,1]$ (recall we assume $\hat{w}_{1}<\tilde{w}$ even for $p=1$ ), and $\bar{L}_{\mathrm{L}}\left(\hat{w}_{1}\right)$ is bounded, there exists $\tilde{p}>0$ such that for all $p>\tilde{p}, \bar{L}_{\mathrm{T}}<\tilde{L}_{\mathrm{S}}$. Also, when $p$ is sufficiently close to zero, $\hat{w}_{1}=\bar{w}$. Now, $\bar{L}_{\mathrm{L}}(\bar{w})<\bar{L}_{\mathrm{S}}(\bar{w})$, for the defendant's winning the first trial in this case completely reveals the marginal type, while settlement results in no learning whatsoever for the defendant. Therefore, by continuity, there exists $\check{p} \in[0,1]$ such that for $p<\breve{p}, \hat{w}_{1}<w^{*}$ and $s\left(\hat{w}_{1}\right)<$ $s^{*}$. The proof when the litigation costs $c+d$ are sufficiently high is similar to this case and omitted.

\section{References}

Arthur, B. 1987. "Self-Reinforcing Mechanisms in Economics," Center for Economic Policy Research Discussion Paper No. 111.

Bebchuk, L. 1984. "Litigation and Settlement under Imperfect Information," 15 RAND Journal of Economics 404-15.

1988. "Suing Solely to Extract a Settlement Offer," 17 Journal of Legal Studies 437-50.

Che, Y.-K., and Yi, J. 1990. "Litigations with Multiple Plaintiffs: The Case of Externality," Center for Economic Policy Research Discussion Paper No. 200.

Currie, D. P. 1957. "Mutuality of Collateral Estoppel: Limits of the Bernhard Doctrine," 9 Stanford Law Review 281-322.

David, P. 1984. "Clio and the Economics of Qwerty," Center for Economic Policy Research Discussion Paper No. 44.

Dungworth, T. 1988. "Product Liability and the Business Sector," Report R-3668-ICJ, Rand Corporation, Santa Monica, Calif.

Friedenthal, J., Kane, M., and Miller, A. 1985. Civil Procedure. St. Paul, Minn.: West.

George, L. C. 1980. "Sweet Uses of Adversity: Parklane Hosiery and the Collateral Class Action," 32 Stanford Law Review 655-86.

Llewellyn, K. 1989. The Case Law System in America (translated by M. Ansaldi). Chicago: University of Chicago Press.

Merryman, J. 1985. The Civil Law Tradition: An Introduction to the Legal Systems of Western Europe and Latin America, 2nd ed. Stanford, Calif.: Stanford University Press.

Milgrom, P. R. 1981. "Good News and Bad News: Representation Theorems and Applications, 12 Bell Journal of Economics 380-91. 
Note, 1992. "Exposing the Extortion Gap: An Economic Analysis of the Rules of Collateral Estoppel," 105 Harvard Law Review 1940-60.

Polasky, A. N. 1954. "Collateral Estoppel-Effects of Prior Litigation," 39 Iowa Law Review 217-99.

Ratliff, J. 1988. "Offensive Collateral Estoppel and the Option Effect," 67 Texas Law Review 63101.

Schroeder, E. P. 1982. "Relitigation of Common Issues: The Failure of Nonparty Preclusion and an Alternative Proposal," 67 lowa Law Review 917-80.

Shavell, S. 1982. "Suit, Settlement, and Trial: A Theoretical Analysis Under Alternative Methods for the Allocation of Legal Costs," 11 Journal of Legal Studies 55-81.

Spurr, S. J. 1991. "An Economic Analysis of Collateral Estoppel," 11 International Review of Law and Economics 47-61. 